\title{
Chemotropism of Achlya bisexualis Germ Hyphae to Casein Hydrolysate and Amino Acids
}

\author{
By A. MUSGRAVE, LOES ERO, R. SCHEFFER \\ AND E. OEHLERS \\ Department of Plant Physiology, Ijdijk 26, \\ Amsterdam, Netherlands
}

(Received I5 November 1976; revised I8 February 1977)

\begin{abstract}
Germ hyphae from zoospores of Achlya bisexualis are positively chemotropic to casein hydrolysate. The active concentration ranges of casein hydrolysate, some amino acid mixtures and single amino acids have been determined. Data on the uptake of amino acids in germlings are presented and discussed in relation to chemotropism.
\end{abstract}

\section{INTRODUCTION}

Chemotropism is the oriented growth of part of an organism in response to a chemical gradient. Together with chemotaxis, where the whole organism moves, it is one of the basic responses of an organism to its environment. However, we have little understanding of the process because the lack of a reliable quantitative assay of chemotropism has so far limited its study. In this report we substantiate a claim by Fischer \& Werner (1955) that germ hyphae of the water mould Achlya bisexualis grow chemotropically to sources of casein hydrolysate and amino acids, and show that the response can be easily quantified.

In chemotropically responding bacteria, amino acid gradients are detected via receptors which are part of the amino acid uptake mechanism (Adler, I975). It seems reasonable to consider whether a similar detection mechanism operates in Achlya. Data on the uptake of amino acids into Achlya germlings have been reported by LeJohn and co-workers (see for example, Singh \& LeJohn, 1975) and providing our two Achlya systems are comparable, we could make use of their data to test this possibility. We present data to show that the amino acid uptake characteristics of our two systems are similar.

\section{METHODS}

Culture methods. Achlya bisexualis (strain 100.42, Centraal Bureau voor Schimmel Cultures, Baarn, Netherlands) was maintained on slopes of corn meal agar at $4{ }^{\circ} \mathrm{C}$. The method of Griffin (I966) was used for the production of zoospores. The fungus was grown for $24 \mathrm{~h}$ in $100 \mathrm{ml}$ medium in $500 \mathrm{ml}$ conical flasks containing $0.125 \mathrm{~g}$ peptone, $0.125 \mathrm{~g}$ yeast extract and $0.5 \mathrm{~g}$ glucose (PYG medium). The mycelium was filtered, washed with approximately $500 \mathrm{ml} 0.5 \mathrm{mM}_{-} \mathrm{CaCl}_{2}$ on the filter and then resuspended in $150 \mathrm{ml}$ $0.5 \mathrm{~mm}_{-\mathrm{CaCl}}$. The next day the mycelium was filtered on a glass-fibre plug, and the spores were concentrated by centrifugation, suspended in fresh $\mathrm{CaCl}_{2}$ solution, reconcentrated and resuspended in fresh $\mathrm{CaCl}_{2}$ solution to give $10^{6}$ spores $\mathrm{ml}^{-1}$ (extinction of 0.45 at $450 \mathrm{~nm}$ ).

Chemotropism tests. (i) Reorientation test. If germ hyphae grow chemotropically to a source of casein hydrolysate, then on changing the position of the source, tip growth should be redirected towards the new position. If the supposed chemotropism results only from the stimulation of mycelial growth near the source of casein hydrolysate, then repositioning the source will not affect the orientation of the original hyphae.

To test how Achlya germ hyphae react, a few drops of spore suspension were evenly spread over a $4 \times 4 \mathrm{~cm}$ block of $\mathrm{I} \cdot 5 \%(\mathrm{w} / \mathrm{v})$ purified agar. A smaller block of agar, containing $50 \mathrm{mg}$ casein hydrolysate $\mathrm{ml}^{-1}$, 

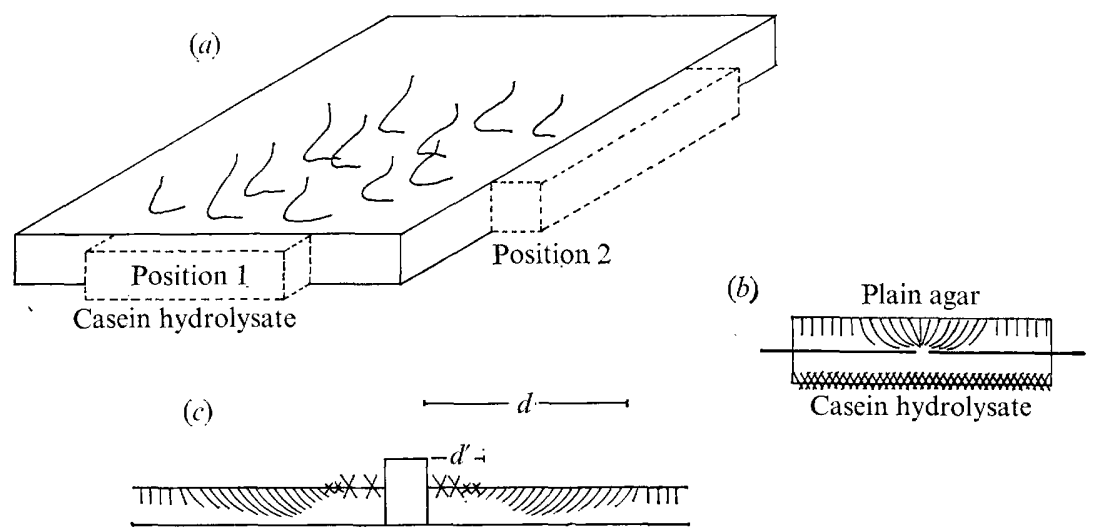

Casein hydrolysate

Fig. I. Chemotropism tests - see Methods for full explanation. (a) Reorientation test; (b) perforated plate test; $(c)$ quantitative test.

was placed in contact with one side of the block (see Fig. $\mathrm{I} a$ ). The spores were allowed to germinate overnight at $27^{\circ} \mathrm{C}$ in the humid atmosphere of a plastic box lined with damp tissue. The next day the casein block was repositioned (as in Fig. I $a$ ) and after another $6 \mathrm{~h}$ the orientation of the hyphae was studied under a binocular microscope.

(ii) Perforated plate test. Robinson (1973) suggested that some claims of chemotropism to nutrient sources can be interpreted as chemotropism to oxygen and not to the test compound. To exclude this possibility the following test, recommended by Dr P. Robinson, was performed. The system represented in Fig. I $(b)$ was constructed. Two circular blocks of $\mathrm{I} .5 \%$ purified agar (diam. $20 \mathrm{~mm}$, depth $3 \mathrm{~mm}$ ) were separated by a thin film of mica with a $0.5 \mathrm{~mm}$ diam. hole at its centre. One of the agar blocks contained $0.1, \mathrm{I} \cdot 0$ or $10.0 \mathrm{mg}$ casein hydrolysate $\mathrm{ml}^{-1}$. One drop of spore suspension was evenly spread over each of the blocks. Spores were left to germinate at $27^{\circ} \mathrm{C}$ in a humid atmosphere and after $\mathrm{I} 8 \mathrm{~h}$ the hyphae on both blocks were observed to see whether they grew towards the hole in the mica.

(iii) Quantitative assay of chemotropism. Ten grooves (100 $\times 10 \times 1.5 \mathrm{~mm})$ were made in the surface of a perspex block and each was filled with $1.6 \mathrm{ml}$ of purified liquid agar $(\mathrm{I} .5 \%)$. Three drops of spore suspension were evenly spread over each agar strip. When dry, a $\mathrm{I} \times \mathrm{I} \mathrm{cm}$ piece was removed from the middle of each strip and a $10 \times 5 \times 5 \mathrm{~mm}$ block containing the test compound was inserted. The remaining parts of the original agar strip were pushed into contact with the test block so that the compound could diffuse towards both ends of the strip. After $20 \mathrm{~h}$ incubation at $27^{\circ} \mathrm{C}$ in a humid atmosphere the strips were observed under a binocular microscope to assess how near to $\left(d^{\prime}\right)$ and how far from $(d)$ the test block chemotropism could be observed (Fig. I $c$ ).

All tests were done in duplicate, giving four values each of $d$ and $d^{\prime}$; these were averaged and plotted against the logarithm of the original concentration in the test block. The points always lay approximately on a straight line and by linear regression analysis of $d$ or $d^{\prime}$ versus $\log _{10}$ concentration, lines of best fit were determined and extrapolated to zero. Thus the lowest $(d)$ and highest $\left(d^{\prime}\right)$ concentrations that support chemotropism were determined.

Amino acid uptake. Spores were germinated by incubating $10 \mathrm{ml}$ spore suspension in $150 \mathrm{ml}$ diluted PYG medium ( $\mathrm{I}: \mathrm{IO}, \mathrm{v} / \mathrm{v})$ in a Fernbach flask as a stationary culture at $14{ }^{\circ} \mathrm{C}$ for $24 \mathrm{~h}$. The $300 \mu \mathrm{m}$ long germlings were collected on a fine nylon gauze filter ( $40 \mathrm{~nm}$ mesh) and suspended in a medium containing Io mM-Tris/acetic acid buffer, $\mathrm{pH} \mathrm{7,2} \mathrm{mM-NaCl,} 2 \mathrm{mM}-\mathrm{KCl}$ and $10 \mathrm{~mm}$-glucose to give an extinction of 0.25 at $200 \mathrm{~nm}$. After incubation at $28^{\circ} \mathrm{C}$ for $45 \mathrm{~min}$, I ml samples were transferred to $\mathrm{I} \mathrm{ml}$ water containing a ${ }^{14} \mathrm{C}$-labelled amino acid. After incubation at $28{ }^{\circ} \mathrm{C}$ the hyphae were rapidly filtered and washed with $15 \mathrm{ml}$ non-radioactive amino acid solution on Sartorius cellulose acetate membrane filters, pore size $0.45 \mu \mathrm{m}$ (Singh \& LeJohn, 1975). In some experiments a duplicate sample was incubated with the ${ }^{14} \mathrm{C}$-labelled amino acid and then transferred to $5 \mathrm{ml} 70 \%(\mathrm{v} / \mathrm{v})$ ethanol at $70{ }^{\circ} \mathrm{C}$, incubated for $5 \mathrm{~min}$ and then filtered as before. All membrane filters were transferred to scintillation vials containing a triton/xylene cocktail (Anderson \& McClure, 1973) and the radioactivity was determined in a Packard liquid scintillation spectrometer fitted with an absolute activity analyser. For each amino acid, uptake was linear for at least the first $3 \mathrm{~min}$ of incubation. The uptake plot was extrapolated to zero time and the value of the intercept on the ordinate was taken as the background count for that particular amino acid and subtracted from all sub- 


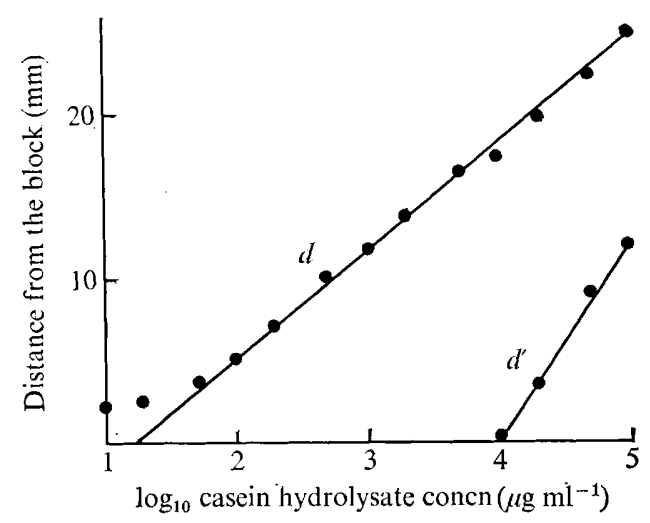

Fig. 2. Determination of the lowest $(d)$ and highest $\left(d^{\prime}\right)$ concentrations of casein hydrolysate that promote chemotropism. Values of $d$ and $d^{\prime}$ were determined as in Fig. I $(c)$.

sequent data. Uptake rates at different amino acid concentrations were determined from duplicate samples taken 3 min after mixing the substrate and hyphae at $28^{\circ} \mathrm{C}$. The $K_{\mathrm{m}}$ and $V_{\max }$ values for each amino acid were calculated from Lineweaver-Burk plots using the lines of best fit as determined by linear regression analysis.

\section{RESULTS}

When spores of $A$. bisexualis germinate on agar they grow vertically down into it. Chemotropism involves changing this orientation so that hyphae grow through the agar parallel to the agar surface. This was best observed by turning the agar gels upside down to look directly at the growing apices. The change of orientation was detected as a mass effect of hundreds or at least tens of hyphae changing their growth direction in accord with a chemical gradient. If this mass effect was not obvious, chemotropism was not registered. Some chemotropic hyphae reorientated and grew at right angles to their first growth direction (see Fig. I $a$ ), although usually they grew in 'slow bends' as represented in Fig. I (c).

Germinating hyphae growing into the agar with the source of casein hydrolysate at position I (Fig. I a) grew towards position I. When the source was moved to position 2, forming a new gradient at right angles to the first, all hyphae over a large area reorientated and grew towards position 2. At regions in the agar block where the casein hydrolysate concentration remained low, the hyphae seldom branched, but whenever this happened, the new hyphae always formed on the source side of the original hyphae and grew straight towards the source. Therefore, although chemotropism to casein hydrolysate involves the reorientation of all pre-existing hyphae, some of the visual effect results from the formation of new apices which do not reorientate. Nevertheless, we emphasize that preexisting apices exhibit genuine chemotropism irrespective of this oriented growth stimulation. Hyphae germinating in very high concentrations of casein hydrolysate branched profusely and tended to grow at or above the agar surface. Those hyphae that did enter the agar did not exhibit chemotropism.

Hyphae germinating on the casein hydrolysate side of the system in Fig. I $(b)$ formed a mat on the agar surface. They did not grow towards the hole in the mica. In contrast, hyphae germinating on the plain-agar side grew towards the hole. At $0.1 \mathrm{mg}$ casein hydrolysate $\mathrm{ml}^{-1}$, the only hyphae that exhibited chemotropism were close to the hole. At Io $\mathrm{mg}$ casein hydrolysate $\mathrm{ml}^{-1}$, hyphae over half the area of the plain-agar block grew towards the hole. Since both agar blocks were seeded with spores, chemotropic growth from the plain-agar surface to the hole cannot be interpreted as growth up an oxygen gradient, 
Table I. Concentrations of casein hydrolysate and amino acid mixtures that induce chemotropism in A. bisexualis hyphae germinating on plain agar

\begin{tabular}{lcc} 
& Active concn $\left(\mu \mathrm{g} \mathrm{ml}^{-1}\right)$ \\
\cline { 2 - 3 } Amino acid mixture & 20 & 10000 \\
Casein hydrolysate & 15 & 3000 \\
Casamino acids & 4 & 125 \\
Ala, Asp, Cys, Glu, Leu, Met, Phe, Val & 8 & 300 \\
Ala, Asp, Cys, Glu, Phe & 20 & 250 \\
Cys, Glu, Phe & 50 & 150 \\
Cys, Glu &
\end{tabular}

especially since the mycelial growth on the casein hydrolysate block was considerably denser than on the plain-agar block.

Plots of casein hydrolysate concentration against $d$ and $d^{\prime}$ (Fig. 2) were linear except at concentrations below $50 \mu \mathrm{g} \mathrm{ml}^{-1}$. This resulted from the fact that hyphae growing next to the test block tended to grow to the block irrespective of whether there was a test compound in it or not. Thus, in practice, $d$ never became zero at low concentrations as it theoretically should. We assume the hyphae were exhibiting negative autotropism, growing away from each other into the test block which represented a region of low cell density. Consequently, all chemotropism directly adjacent to the blocks was ignored. The approximate straight lines were extrapolated to zero. The two intercepts on the $x$-axis gave values of 20 and $10000 \mu \mathrm{g} \mathrm{ml}^{-1}$ for the lowest and highest concentrations of casein hydrolysate that supported chemotropism. These concentrations represent the limits of the activity range of casein hydrolysate. The lower limit closely coincided with the lowest concentration of casein hydrolysate that stimulated hyphal growth. Consequently, hyphae growing at these lower concentrations seldom branched and, when viewed under the microscope, it was clear which hyphae had reorientated toward the test block. In contrast, chemotropism at concentrations near the upper limit of the activity range was not determined so easily, for the hyphae branched frequently, tended to remain at the agar surface and those hyphae growing into the agar did not penetrate far.

A mixture of free amino acids purified from casein hydrolysate (Casamino acids, Difco) was also chemotropically active (Table I) and therefore individual free L-amino acids were tested for activity. With the exception of cysteine which sometimes gave a weak response, no single amino acid was active. In contrast, they were active in combination, and Table I shows data for a few such mixtures. Some mixtures were more active (i.e. gave a response at lower concentrations) than casein hydrolysate but for all combinations that were tested the range of activity was limited in comparison with casein hydrolysate, and the fewer amino acids present the narrower the range of activity. The simplest active mixture of the eight amino acids listed in Table I was cysteine plus aspartic or glutamic acid.

Chemotropism to single amino acids was observed when a background of casein hydrolysate $\left(200 \mu \mathrm{g} \mathrm{ml}^{-1}\right)$ was incorporated in the agar strips in the quantitative assay. Using this modification the responses to the L-amino acids could be quantified (Table 2). Nine D-amino acids (Ala, Ile, Leu, Met, Phe, Ser, Thr, Trp and Val) tested in the same manner were inactive. The upper limits of the activity ranges of aspartic and glutamic acids were not determined because both inhibited growth at high concentrations due to the low $\mathrm{pH}$. The low solubility of tyrosine also made it impossible to determine its upper limit. Nevertheless, in principle, the assay enabled us to quantify the chemotropic responses to all active amino acids, and other active compounds or mixtures could be assayed in the same manner.

There is no obvious correlation between the $K_{\mathrm{m}}$ and $V_{\max }$ values for the uptake of 
Table 2. Chemotropic and uptake characteristics of amino acids in A. bisexualis germlings

\begin{tabular}{|c|c|c|c|c|}
\hline \multirow{2}{*}{$\begin{array}{l}\text { Amino } \\
\text { acid }\end{array}$} & \multicolumn{2}{|c|}{$\begin{array}{l}\text { Chemotropism* } \\
\text { Active concn }(\mu \mathrm{M})\end{array}$} & \multirow{2}{*}{$\begin{array}{c}K_{\mathrm{m}} \\
(\mu \mathrm{M})\end{array}$} & \multirow{2}{*}{$\begin{array}{c}V_{\max } \\
{\left[\mathrm{nmol} \mathrm{min}^{-1}\right.} \\
\left.(\mathrm{mg} \text { dry wt })^{-1}\right]\end{array}$} \\
\hline & Lowest & Highest & & \\
\hline $\begin{array}{l}\text { Met } \\
\text { Trp }\end{array}$ & $\begin{array}{l}7 \cdot 9 \\
8 \cdot 3\end{array}$ & $\begin{array}{l}53 \\
64\end{array}$ & 130 and 12 & 53 and 14 \\
\hline Phe & 32 & 240 & 58 & 72 \\
\hline Leu & 34 & 120 & 14 & I3 \\
\hline Ala & 47 & 660 & & \\
\hline Thr & 66 & 260 & & \\
\hline Ser & 80 & 450 & & \\
\hline Ile & 98 & 240 & & \\
\hline Hyp & 120 & 380 & & \\
\hline Tyr & 140 & ND & & \\
\hline Val & 140 & 950 & 95 & 44 \\
\hline $\mathrm{His}$ & 160 & 1900 & I 10 & 49 \\
\hline Cys & 460 & 1500 & 65 & 4 \\
\hline Asp & 500 & ND & 28 & 4 \\
\hline Glu & 940 & ND & & \\
\hline Arg & & & & \\
\hline Asn & & • & 49 & I3 \\
\hline Gln & & & & \\
\hline Gly & & & & \\
\hline Lys & & & & \\
\hline Pro & & & 74 & $8 I$ \\
\hline
\end{tabular}

amino acids (Table 2) and chemotropic sensitivities to the amino acids. To establish whether our Achlya germling system was equivalent to that described by LeJohn and co-workers, we plotted our $K_{\mathrm{m}}$ values against those reported by Singh \& LeJohn (1975); with the exception of the value for leucine, the points lay approximately on a straight line. The correlation coefficient was 0.9I $(P<0.0 \mathrm{I})$ indicating that the uptake characteristics of both systems are very similar and that one might therefore justifiably relate their findings to this chemotropic system.

\section{DISCUSSION}

We have confirmed that $A$. bisexualis germ hyphae are positively chemotropic to casein hydrolysate and amino acids. A low level of casein hydrolysate was required by the germlings, presumably as a nutrient source, before they exhibited chemotropism to single amino acids. Free amino acids in the hydrolysate may affect the quantitative assay, and therefore we have tried to replace it with non-amino acid nutrients, but as yet without success.

It is important to consider what the fungus detects when sensing a gradient. Does it, for example, detect the compound itself, or the energy of metabolism or a metabolite? The energy of metabolism seems unlikely to be detected because the ability of an amino acid to stimulate growth (a measure of energy production) is not correlated with the ability to stimulate chemotropism. It is therefore more plausible to consider that the fungus detects the amino acids per se or specific metabolites of them. This entails possessing specific receptors to sense the gradients of these compounds. In chemotactic bacteria the receptors are part of the uptake mechanism (Adler, 1975) and it is reasonable to consider that $A$. bisexualis germlings use a similar mechanism. Singh \& LeJohn (1975) showed that 
all amino acids enter Achlya germlings by active uptake mechanisms, that some of the amino acids enter by a common uptake mechanism and that uptake of an amino acid can be competitively inhibited by others using the same mechanism.

We gratefully acknowledge the helpful advice of Dr H. van den Ende and Dr P. Robinson.

\section{REFERENCES}

Adler, J. (1975). Chemotaxis in bacteria. Annual Review of Biochemistry 44, 34I-356.

Anderson, L. E. \& McClure, W. O. (1973). An improved scintillation cocktail of high-solubilizing power. Analytical Biochemistry 51, I73-I79.

Fischer, F. G. \& Werner, G. (I955). Eine Analyse des Chemotropismus einiger Pilze, insbesondere der Saprolegniaceen. Hoppe-Seyler's Zeitschrift für physiologische Chemie 300, 2 I I-236.

GRIFFIN, D. H. (I966). Effect of electrolytes on

differentiation in Achlya sp. Plant Physiology 4r, I254-I256.

Robinson, P. M. (1973). Chemotropism in fungi. Transactions of the British Mycological Society 6r, 303-313.

Singh, D. J. \& LeJohn, H. B. (1975). Amino acid transport in a water mold: the possible regulatory roles of calcium $N^{6}$-( $\Delta^{2}$-isopentenyl)adenine. Canadian Journal of Biochemistry 53, 975-988. 